\title{
Omentectomy in Combination With Hysterectomy As a Remedial Procedure Improves Disease-Free Survival of Patients With Occult Uterine Sarcoma Undergoing Morcellation: A Retrospective Study
}

Chao Ding

Zhejiang Cancer Hospital https://orcid.org/0000-0002-4575-301X

Jianqing Zhu ( $\nabla$ zhujq@zjcc.org.cn )

https://orcid.org/0000-0001-5736-7397

Research article

Keywords: Uterine sarcoma, Tumor morcellation, Remedial procedure

Posted Date: April 5th, 2021

DOI: https://doi.org/10.21203/rs.3.rs-386989/v1

License: (a) (1) This work is licensed under a Creative Commons Attribution 4.0 International License.

Read Full License 


\section{Abstract}

Background囚Tumor morcellation happened to facilitate iatrogenic metastasis for patients with occult uterine sarcoma. The optimal remedial procedure for these patients needed to be established. Methods $\llbracket$ Data were retrospectively collected and analyzed from patients with occult uterine sarcoma undergoing morcellation. Results冈23 consecutive patients with uterine sarcomas undergoing morcellation were accessed between Jan 2008 and Dec 2018, including 15 patients with uterine leiomyosarcoma and 8 with endometrial stromal sarcoma. Hysterectomy + omentectomy as a remedial procedure was significantly associated with better disease-free survival $(P=0.031)$, and all 7 patients undergoing the previous procedure remain disease free. However, nether simple hysterectomy ( $P=0.194)$ nor adjuvant therapy $(P=0.159)$ had such benefits. There was no significant difference in disease-free survival between laparoscopic and open surgery $(p=0.321)$. ConclusionखHysterectomy + omentectomy was considered as the optimal remedial procedure for patients with occult uterine sarcoma undergoing morcellation.

\section{Background}

Uterine sarcoma is a rare solid malignant tumor in uterine accounting for less than $3 \%$ of all female reproductive system malignancies [1]. The incidence of sarcomatous transformation in benign leiomyoma is $0.13 \% \sim 0.81 \%$ [2]. The major histological types involve uterine leiomyosarcoma (LMS) (accounting for $30 \sim 40 \%$ of uterine sarcomas), and endometrial stromal sarcoma (ESS) (10-15\%) [3]. Complete tumor resection is the only effective modality, while other modalities, such as radiation therapy, chemotherapy, hormone therapy, targeted therapy, or any of their combinations, are not effective [4].

It is difficult to distinguish occult uterine sarcoma from other benign uterine tumors before surgery [5]. There are patients with occult uterine sarcoma underwent laparoscopic surgery with morcellation by accident. A power morcellator is a surgical instrument used for division and removal of large masses of tissues during laparoscopic surgery. In cases of myomectomy or supracervical hysterectomy, the tissue has to be morcellated before extraction. Some studies showed the tumor morcellation utilized in patients with uterine sarcoma increased the rate of pelvic recurrence, facilitated abdominal dissemination and induced poor prognosis [6-11]. It is worth noting that morcellation leads to significantly poorer DFS of patients with ESS $(\mathrm{OR}, 4.03 ; 95 \% \mathrm{Cl}, 1.06-15.30 ; \mathrm{P}=0.040)$ [9]. In 2014 FDA stated that tumor morcellation used for laparoscopic myomectomy or hysterectomy is associated with increased risk for spreading cancer and so that restrict the usage of tumor morcellation [12]. Some study found the prevalence of occult leiomyosarcoma at surgery for presumed uterine fibroids were $1 / 8300$ [13] or 1/10000-13/10000 [14], lower than the prevalence evaluated by FDA (1/498).

However, which type of remedial procedure should be taken to benefit these patients remained unclear. A previous study indicated patients who underwent completion surgery with restaging and are not upstaged appeared to have a good prognosis [15]. 
Which kind of modality can be taken as an effective remedial procedure? According to the 2020 NCCN clinical practice guideline on uterine neoplasms, simple hysterectomy \pm oophorectomy was enough for early uterine sarcoma. Was it also enough for the patients undergoing unexpected morcellation? Was it necessary to perform omentectomy typically even if no macroscopic residuals were found during secondary surgery? Can adjuvant therapy be helpful for these patients?

Our study tried to find an optimal option for remedial therapy for these patients.

\section{Materials And Methods}

\section{Study population}

The data of consecutive patients with LMS and ESS who were treated and followed at Zhejiang Cancer Hospital (Hangzhou, Zhejiang, China) were collected from 2008 to 2018. The data included patient age, menopausal status, and body mass index; clinicopathologic data including International Federation of Obstetrics and Gynecology (FIGO) stage, mitotic count, tumor grade, the interval between the initial surgery and re-operation, residuals after the initial surgery, and adjuvant therapy; and follow-up data including tumor recurrence, location of recurrent tumor, and death. Pathologic slides were all reviewed by two pathologists. We analyzed the data of all patient undergoing morcellation to determine which type of remedial procedure could improve the prognosis. Outcomes included rate of cumulative recurrence, 1-year disease-free survival rate and odd ratio of risk of recurrence.

\section{Statistical analysis}

Means and median values were compared using Student's t-test and frequency distributions were compared using chi-squared and Fisher's exact tests. DFS was calculated as the number of months from the date of surgery to either date of recurrence or date censored. Survival curves and rates were calculated using the Cox regression analysis. Univariate and multivariate analyses were performed using Cox's proportional hazards model, with multivariate analysis including at least 2 factors significant in univariate analysis. Two-sided P-values less than 0.05 were considered statistically significant. All statistical analyses were performed using SPSS software for Windows (version 17.0; SPSS Inc., Chicago, IL).

\section{Results}

23 patients with uterine sarcoma were treated and followed at Zhejiang Cancer Hospital, including 15 patients with LMS and 8 with ESS. The median follow-up times were 23 months (range, 5-106 months) for all patients. The characteristics of patients were present in Table 1. 
Table 1

Characteristics of patients with uterine sarcoma $(n=23)$

\section{Characteristics of patients}

Age

Mean \pm SD

$44.9 \pm 7.2$

Menopause, $n(\%)$

No

19(82.6)

Yes

$4(17.4)$

Body mass index

Mean \pm SD

$22.6 \pm 2.3$

Initial symptoms, n (\%)

Asymptomatic

14(60.9)

Palpable mass

$4(17.4)$

Vaginal bleeding

$4(17.4)$

Abdominal pain

2(8.7)

Preoperative presumptive diagnosis, $\mathrm{n}(\%)$

Uterine sarcoma

$0(0)$

Uterine leiomyoma

23(100)

Initial operation was performed at, n(\%)

Zhejiang Cancer Hospital

$0(0)$

Other hospital

23(100)

Initial operation, $\mathrm{n}(\%)$

Myomectomy

18(78.3)

Supracervical hysterectomy

$4(17.4)$

Hysterectomy

1(4.3)

Pathological type, n (\%)

Uterine leiomyosarcoma

15(65.2)

Endometrial stromal sarcoma

8(34.8)

FIGO stage, $\mathrm{n}(\%)$ ।

17(73.9)

II

2(8.7)

III

4(17.4)

Mitotic count, $\mathrm{n}(\%)$

$<5 / 10 \mathrm{HPF}$

18(78.3)

$\geq 5 / 10 \mathrm{HPF}$

$5(21.7)$

Grade of tumor, n (\%)

Low

18(78.3)

High

$5(21.7)$

SD, standard deviation; PLND, pelvic lymph node dissection; PALND, para-aortic lymph node dissection.

According to Table 2, there were no significant differences between groups in age, menopausal status, and FIGO stage. 
In 23 patients, 4 patients refused re-operation, 12 patients underwent simple hysterectomy \pm oophorectomy, and 7 patients underwent omentectomy in combination with hysterectomy \pm oophorectomy. No patients have macroscopic extra-uterine residuals before secondary surgery. Ten of 23 patients underwent adjuvant therapy. Adjuvant therapy contained chemotherapy, radiotherapy and hormone therapy.

We found that hysterectomy + omentectomy could improve the disease-free survival compared with the no re-operation group $(\mathrm{OR}, 0.17 ; 95 \% \mathrm{Cl}, 0.03-0.85 ; \mathrm{P}=0.031)$ (Table 2$)$. All 7 patients performing hysterectomy + omentectomy remain disease free. However, simple hysterectomy \pm oophorectomy $(P=$ $0.194)$ and adjuvant therapy $(P=0.159)$ seemed no association with the DFS. Six of 12 patients undergoing simple hysterectomy \pm oophorectomy suffered recurrence. Whether to take Laparoscopic surgery or abdominal surgery also seem no significant difference between each other $(p=0.321)$. 
Table 2

Re-operation and adjuvant therapy associated with disease-free survival of patients undergoing tumor morcellation $(\mathrm{n}=23)$

\begin{tabular}{|c|c|c|c|c|c|c|}
\hline & & $\begin{array}{l}\text { Total, } \\
\mathrm{n}\end{array}$ & $\begin{array}{l}\text { Recur, } \\
\text { n(\%) }\end{array}$ & $\begin{array}{l}\text { 1-year } \\
\text { DFS(\%) }\end{array}$ & $\begin{array}{l}\text { Odd } \\
\text { ratio(95\% } \mathrm{Cl})\end{array}$ & $\begin{array}{l}\mathrm{P}- \\
\text { value }\end{array}$ \\
\hline \multirow[t]{2}{*}{ Age } & $\leq 47$ years & 10 & $5(50.0)$ & 48.5 & 1 & \\
\hline & $₫ 47$ years & 13 & $5(38.5)$ & 80 & $\begin{array}{l}0.74(0.20- \\
2.80)\end{array}$ & 0.662 \\
\hline \multirow[t]{2}{*}{ Menopause } & No & 19 & $7(36.8)$ & 82.5 & 1 & \\
\hline & Yes & 4 & $3(75.0)$ & 50 & $\begin{array}{l}0.97(0.19- \\
4.87)\end{array}$ & 0.968 \\
\hline \multirow[t]{2}{*}{ FIGO stage } & I & 17 & $5(29.4)$ & 86.2 & 1 & \\
\hline & II and III & 6 & $5(83.3)$ & 50 & $\begin{array}{l}3.58(0.93- \\
13.77)\end{array}$ & 0.063 \\
\hline \multirow[t]{2}{*}{ Histological types } & LMS & 15 & $8(53.3)$ & 71.8 & 1 & \\
\hline & ESS & 8 & $2(25.0)$ & 57.1 & $\begin{array}{l}0.60(0.12- \\
3.07)\end{array}$ & 0.539 \\
\hline \multirow{3}{*}{$\begin{array}{l}\text { Interval between } \\
\text { first operation and } \\
\text { re-operation }\end{array}$} & \30 days & 14 & $5(35.7)$ & 91.7 & 1 & \\
\hline & $\geq 30$ days & 5 & $1(20.0)$ & 75 & $\begin{array}{l}1.07(0.12- \\
9.75)\end{array}$ & 0.95 \\
\hline & no re-operation & 4 & $4(100.0)$ & 25 & $\begin{array}{l}4.81(1.12- \\
20.64)\end{array}$ & $0.035^{*}$ \\
\hline \multirow{3}{*}{$\begin{array}{l}\text { Types of re- } \\
\text { operation }\end{array}$} & no re-operation & 4 & $4(100.0)$ & 25 & 1 & \\
\hline & $\begin{array}{l}\text { Simply } \\
\text { hysterectomy } \pm \\
\text { oophorectomy }\end{array}$ & 12 & $6(50.0)$ & 75 & $\begin{array}{l}0.31(0.05- \\
1.83)\end{array}$ & 0.194 \\
\hline & $\begin{array}{l}\text { hysterectomy }+ \\
\text { omentectomy } \pm \\
\text { oophorectomy }\end{array}$ & 7 & $0(0)$ & 91.7 & $\begin{array}{l}0.17(0.03- \\
0.85)\end{array}$ & $0.031 *$ \\
\hline \multirow[t]{2}{*}{ Adjuvant therapy } & No & 13 & $9(69.2)$ & 61.5 & 1 & \\
\hline & Yes & 10 & $1(10.0)$ & 100 & $\begin{array}{l}0.22(0.03- \\
1.81)\end{array}$ & 0.159 \\
\hline $\begin{array}{l}\text { DFS, disease-free s } \\
\text { Gynecology; } *, p<0\end{array}$ & val; $\mathrm{Cl}$, confidenc & I; FIC & Internati & Feder & of Obstetri & \\
\hline
\end{tabular}


Our study summarized the data of every recurrence of patients in Table 3 . About $47.8 \%$ patients experienced the recurrence 14 months (4-56 months) after the initial surgery. The disease-free intervals between recurrence became shorter and shorter. The recurrence was the most likely to occur in the pelvis. Peritoneal and gastrointestinal implantation was the most common form of cancer metastasis, while pelvic and para-aortic lymph metastasis was rare.

There were 4 patients in our study never undergoing any remedial procedures after taking morcellation by accident. The reasons include misdiagnosis of pathology and personal rejection. These patients suffered at least two recurrences. One patient died of uncontrolled abdominal tumor bleeding after four recurrences. 
Table 3

Anatomical location of recurrent disease at every recurrence $(n=23)$.

\begin{tabular}{|c|c|c|c|c|c|}
\hline Recurrence & & $\begin{array}{l}\text { First } \\
\text { recurrence }\end{array}$ & $\begin{array}{l}\text { Second } \\
\text { recurrence }\end{array}$ & $\begin{array}{l}\text { Third } \\
\text { recurrence }\end{array}$ & $\begin{array}{l}\text { Forth } \\
\text { recurrence }\end{array}$ \\
\hline$n(\%)$ & & $11(47.8)$ & $8(34.8)$ & $4(17.4)$ & $1(4.3)$ \\
\hline Death, $n$ & & 1 & 0 & 2 & 1 \\
\hline $\begin{array}{l}\text { Disease-free interval } \\
\text { before } \\
\text { recurrence(month) }\end{array}$ & Median(range) & $14(4-56)$ & $3.5(2-31)$ & $7.5(7-21)$ & 12 \\
\hline \multirow[t]{2}{*}{ Pathological type } & $\begin{array}{l}\text { Uterine } \\
\text { leiomyosarcoma }(\mathrm{n}= \\
\text { 15) }\end{array}$ & 9 & 7 & 3 & 1 \\
\hline & $\begin{array}{l}\text { Endometrial stromal } \\
\text { sarcoma }(\mathrm{n}=8)\end{array}$ & 2 & 1 & 1 & 0 \\
\hline \multirow[t]{11}{*}{$\begin{array}{l}\text { Anatomical location } \\
\text { of recurrence }\end{array}$} & $\begin{array}{l}\text { Pelvis (without } \\
\text { rectum and lymph } \\
\text { nodes) }\end{array}$ & 6 & 7 & 3 & 1 \\
\hline & Pelvic lymph nodes & 1 & 0 & 1 & 0 \\
\hline & Rectum & 2 & 4 & 0 & 0 \\
\hline & $\begin{array}{l}\text { Colon(without } \\
\text { rectum) }\end{array}$ & 3 & 3 & 0 & 0 \\
\hline & Small intestine & 4 & 2 & 0 & 0 \\
\hline & $\begin{array}{l}\text { Peritoneum (not in } \\
\text { the pelvis) }\end{array}$ & 2 & 2 & 0 & 0 \\
\hline & Omentum & 0 & 1 & 0 & 0 \\
\hline & Pancreas & 0 & 1 & 0 & 0 \\
\hline & Liver & 0 & 0 & 1 & 0 \\
\hline & Abdominal wound & 0 & 1 & 0 & 0 \\
\hline & Lung & 1 & 1 & 1 & 0 \\
\hline
\end{tabular}

\section{Discussion}

To our knowledge, the FDA stated that tumor morcellation promoted an adverse effect on the prognosis of patients with LMS [12]. Jeong-Yeol Park et al confirmed that tumor morcellation facilitated recurrence in peritoneal cavity and adversely affected DFS(OR, 2.59;95\% Cl, 1.03-6.50; $\mathrm{P}=0.043)$ and $\mathrm{OS} \square \mathrm{OR}, 3.07$; $95 \% \mathrm{Cl}, 1.05-8.93 ; \mathrm{P}=0.040 \mathrm{Q}$ in patients with uterine LMS [6]. They also found tumor morcellation was associated with a significantly higher rate of abdominopelvic recurrence and significantly poorer DFS 
$(\mathrm{OR}, 4.03 ; 95 \% \mathrm{Cl}, 1.06-15.30 ; \mathrm{P}=0.040)$ in patients with $\mathrm{ESS}$, but OS was not significantly compromised [8]. Another research with 123 patients found the rate of pelvic recurrence 3 months after surgery was higher in the morcellation group than in the non-morcellation group, but the difference was not statistically significant ( $8.8 \%$ vs. $3.6 \%, P=0.25)$ [7].

Our study found $47.8 \%$ of patients suffered sarcoma recurring. It was much frequently that the recurrence occurred in the pelvis where former primary lesion was located. The peritoneal and gastrointestinal implantation in upper abdomen were also common.

In our study, omentectomy along with hysterectomy as a remedial procedure was very important for those patients to improve DFS $(\mathrm{OR}, 0.17 ; 95 \% \mathrm{Cl}, 0.03-0.85 ; \mathrm{P}=0.031)$, no matter how long of the interval between the initial surgery and re-operation ( $₫ 30$ days vs. $\geq 30$ days, $P=0.950$ ). Additional surgical resection for intraoperative discovery of extrauterine disease should be individualized.

All 7 patients undergoing hysterectomy + omentectomy remained disease free while six of 12 patients undergoing simple hysterectomy suffered recurrence. Simple hysterectomy $(P=0.194)$ and adjuvant therapy $(P=0.159)$ seemed not to impact the DFS. A previous retrospective study showed that two of 13 patients with uterine malignancy underwent paracervical hysterectomy during the initial surgery was upstaged by re-exploration; both had LMS originally resected with morcellation. Patients who underwent completion surgery with restaging appeared to have a good prognosis [15]. Moreover, re-operation long after the initial surgery ( $\geq 30$ days) with morcellation can still be valuable. Cao $\mathrm{H}$ et al also confirmed that the time interval between initial treatment and secondary definitive surgery was not shown to impact prognosis [16].

The limitation of our study included the retrospective design and the relatively small number of patients. The small number of uterine sarcoma patients having morcellation (15 LMS and 8 ESS) may be underpowered to detect differences in survival.

\section{Conclusion}

Omentectomy in combination with hysterectomy as a remedial procedure decrease the DFS of all patients with occult uterine sarcoma undergoing morcellation by accident.

\section{Abbreviations}

Cl: confidence interval

DFS: disease-free survival

ESS: Uterine endometrial stromal sarcoma.

FIGO: International Federation of Obstetrics and Gynecology 
HPF: high power filed

LMS: Uterine leiomyosarcoma

NA: not applicable

OS: overall survival

\section{Declarations}

\section{Availability of data and materials}

The datasets used or analyzed during the current study are available from the corresponding author on reasonable request.

\section{Ethics approval and consent to participate}

All procedures performed in studies involving human participants were in accordance with the ethical standards of the institutional and/or national research committee and with the 1964 Helsinki declaration and its later amendments or comparable ethical standards. This research was approved by the ethics committee of Zhejiang Cancer Hospital. The reference number was IRB-2019-199.

\section{Consent for publication}

Not applicable.

\section{Competing interests}

All authors report no conflict for interest for this research paper.

\section{Funding}

None.

\section{Authors' information}

Affiliations

Department of Gynecological Oncology, Hospital of the University of Chinese Academy of Sciences

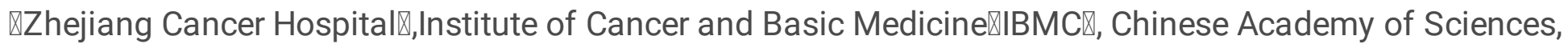
Hangzhou 310022, China.

Chao Ding, Jianqing Zhu

\section{Authors' contributions}


Guarantor of integrity of the entire study: Jianqing Zhu. Study concepts: Jianqing Zhu, Chao Ding. Study design: Jianqing Zhu, Chao Ding. Collection of data: Chao Ding. Data analysis: Chao Ding. Statistical analysis: Chao Ding. Manuscript preparation: Chao Ding. Manuscript editing: Chao Ding. Manuscript review: Jianqing Zhu. The authors read and approved the final manuscript.

\section{Corresponding author}

Correspondence to Jianqing Zhu

\section{Acknowledgements}

None.

\section{References}

[1] Olah KS, Gree H, Blunt S, et al. Retrospective analysis of 318 cases of uterine sarcoma. Eur J Cancer 1991; 27: 1095-1099.

[2] Berchuch A, Rubin SC, Hoskins WJ, Saigo PE, Pierce VK, Lewis JL Jr. Treatment of uterine leiomyosarcoma. Obstet Gynecol. 1988;71: 845-850.

[3] Tavassoéli FA, Devilee P.. World Health Organization classification of tumours In: Pathology and genetics of tumors of the breast and female genital organs.4th ed. IARC Press : Lyon, 2003

[4] Nam J.H., Park J.Y. Update on treatment of uterine sarcoma. Curr Opin Obstet Gynecol. 2010; 22: 3642.

[5] Amant F, Coosemans A, Debiec-Rychter M, Timmerman D, Vergote I. Clinical management of uterine sarcomas. Lancet Oncol. 2009; 10: 1188-1198.

[6] Anupama R, Ahmad SZ, Kuriakose S, et al. Disseminated peritoneal leiomyosarcomas after laparoscopic "myomectomy" and morcellation. J minim invasive gynecol, 2011, 18(3): 386-389.

[7] Morice P, Rodriguez A, Rey A, et al. Prognostic value of initial surgical procedure for patients with uterine sarcoma: analysis of 123 patients[J]. Eur J Gynaecol Oncol, 2003, 24(3-4): 237-240 (2003).

[8] Park JY, Park SK, Kim DY, et al. The impact of tumor morcellation during surgery on the prognosis of patients with apparently early uterine leiomyosarcoma. Gynecol Oncol, 2011, 122(2): 255-259.

[9] Park JY, Kim DY, Kim JH, et al. The impact of tumor morcellation during surgery on the outcomes of patients with apparently early low-grade endometrial stromal sarcoma of the uterus. Ann Surg Oncol, 2011, 18(12): 3453-3461.

[10] Della BC, Karini H. Endometrial stromal sarcoma diagnosed after uterine morcellation in laparoscopic supracervical hysterectomy. J Minim Invasive Gynecol, 2010, 17(6): 791-793. 
[11] Rekha W, Amita M, Sudeep G, et al. Unexpected complication of uterine myoma morcellation. Aust N Z J Obstet Gynaecol. 2005, 45(3): 248-24.

[12] US Food and Drug Administration. Quantitative assessment of the prevalence of unsuspected uterine sarcoma in women undergoing treatment of uterine fibroids: summary and key findings[EB/OL].

Maryland: FDA Safety Communication, 2014[2020-03-10]. https://www.fda.gov/media/88703/download.

[13] Pritts EA, Vanness DJ, Berek JS, et al. The prevalence of occult leiomyosarcoma at surgery for presumed uterine fibroids: a meta-analysis. Gynecol Surg 2015; 12:165-177.

[14] Hartmann KE, Fonnesbeck C, Surawicz T, et al. Management of Uterine Fibroids [M/OL]. Rockville: Agency for Healthcare Research and Quality, 2017[2020-3-10]. https://www.ncbi.nlm.nih.gov/books/NBK537742/.

[15] Einstein MH, Barakat RR, Chi DS, et al. Management of uterine malignancy found incidentally after supracervical hysterectomy or uterine morcellation for presumed benign disease. International J Gynecol Cancer, 2008, 18(5): 1065-1070.

[16] Cao H, Li L, Yang B, Luo G, et al. Unexpected uterine sarcomas after hysterectomy and myomectomy for presumed leiomyoma: a retrospective study of 26,643 patients. Cancer Manag Res. 2019 Jul 25; 11: 7007-7014. 